\title{
Influence of harvest, climate and wolf predation on Yellowstone elk, 1961-2004
}

\author{
John A. Vucetich, Douglas W. Smith and Daniel R. Stahler
}

\begin{abstract}
Vucetich, J. A., Smith, D. W. and Stahler, D. R. 2005. Influence of harvest, climate and wolf predation on Yellowstone elk, 1961-2004. - Oikos 111: 259-270.

In the period following wolf (Canis lupus) reintroduction to Yellowstone National Park (1995-2004), the northern Yellowstone elk (Cervus elaphus) herd declined from $\sim 17000$ to $\sim 8000 \mathrm{elk}\left(8.1 \% \mathrm{yr}^{-1}\right)$. The extent to which wolf predation contributed to this decline is not obvious because the influence of other factors (human harvest and lower than average annual rainfall) on elk dynamics has not been quantified. To assess the contribution of wolf predation to this elk decline, we built and assessed models based on elk-related data prior to wolf reintroduction (1961 to 1995). We then used the best of these models to predict how elk dynamics might have been realized after wolf reintroduction (1995 to 2004) had wolves never been reintroduced. The best performing model predicted $64 \%$ of the variance in growth rate and included elk abundance, harvest rate, annual snowfall, and annual precipitation as predictor variables. The best performing models also suggest that harvest may be super-additive. That is, for every one percent increase in harvest rate, elk population growth rate declines by more than one percent. Harvest rate also accounted for $\sim 47 \%$ of the observed variation in elk growth rate. According to the best-performing model, which accounts for harvest rate and climate, the elk population would have been expected to decline by $7.9 \%$ per year, on average, between 1995 and 2004. Within the limits of uncertainty, which are not trivial, climate and harvest rate are justified explanations for most of the observed elk decline. To the extent that this is true, we suggest that between 1995 and 2004 wolf predation was primarily compensatory.
\end{abstract}

J. A. Vucetich, School of Forest Resources \& Environmental Science, Michigan Tech. Univ., Houghton, MI 49931, USA (javuceti@mtu.edu). - D. W. Smith and D. R. Stahler, National Park Service, Yellowstone Center for Resources, P.O. Box 168, Yellowstone National Park, WY 82190, USA.

The influence of predation on prey population dynamics is varied and complex. Meta-analysis of controlled experiments suggests that predation sometimes, but not always, results in a trophic cascade (Schmitz et al. 2000). Nonexperimental introductions of carnivores appear to be associated with prey declines in about half the cases (Ebenhard 1988). The influence of predation is also suggested by the tendency for prey populations to exist at lower densities when exposed to predator communities with increased species richness (Peterson 2001, Mech and Peterson 2002). However, the widespread tendency for carnivore and prey populations to be positively correlated (over time and across space, Fuller and Sievert 2001), may indicate that predator equilibria are importantly determined by prey equilibria, rather than the reverse.

A useful approach for understanding variations in the effect of predation is synthetic analysis (Sinclair 2003, Sinclair et al. 2003) of individual case studies (Mduma et al. 1999, Dumont et al. 2000, Grange et al. 2004, Joly and Messier 2004). Such analysis depends on the accumulation of case studies.

Knowledge concerning predation effects on prey is often inadequate for effective conservation and

Accepted 25 April 2005 
management. For example, seal (Pagophilus groenlandicus and Halichoerus grypus) harvests off the east coast of Canada are motivated by the belief that seals compete with humans for fish. The harvest is controversial, in part, because the actual influence of predatory seals is uncertain (Yodzis 2001). Similar situations exist for wolf-moose-human systems in Alaska (National Research Council 1997), and for cormorant-herringhuman systems in the Great Lakes, North America (Stapanian and Bur 2002).

Given the preceding contexts, an important case for study is the influence of predation on prey dynamics is the restoration of wolves (Canis lupus) to the Northern Range of Yellowstone National Park (YNP; in Wyoming and Montana, USA), where a large herd of elk (Cervus elaphus) resides. The elk population was monitored prior to (1961-1995) and after (1995-2004) the reintroduction of wolves (Houston 1982, Lemke et al. 1998, YNP, unpubl.). Since the wolf reintroduction, estimated elk abundance has declined. Superficially, the decline may reasonably be attributed to wolf predation. One population model, prepared prior to wolf reintroduction indicates that wolves would cause elk to eventually decline by approximately $10-30$ percent (Boyce and Gaillard 1992, Boyce 1993). Some familiar with the system believe elk will decline substantially more than this (Messier et al. 1995), and others substantially less than this (Mack and Singer 1993). Understanding the influence of wolf reintroduction on elk dynamics is complicated by the influence of human harvest and climate, which are known to importantly affect elk population dynamics (Bender and Miller 1999, Biederbeck et al. 2001, Wang et al. 2002). Specifically, since wolf reintroduction, the Northern Range has experienced a severe multi-year drought and an increased average annual rate of harvest.

In this paper, we empirically quantify the extent to which wolves may have contributed to the observed decline in elk abundance. We do this by building several time series models of elk population growth rate based on data prior to the wolf reintroduction (1961-1995). We then project these model predictions on the basis of covariate values (e.g. harvest and climate) observed each year since wolf reintroduction. Conceptually, the difference between the predicted and observed trajectory of elk is the estimated contribution of wolves to the observed elk decline.

\section{Data sources and preparation}

\section{Elk data}

Elk have been counted by aerial survey during most years between 1961 and 2004 (Table 1). The methods are described and data presented in Taper and Gogan (2002) and in Lemke et al. (1998). Data since 1995 were obtained from annual reports of the elk count and elk harvest (Montana Fish Wildlife and Parks 2004).

Each year elk are counted in December or early January. Since 1976, this elk population has been harvested during four separate annual hunts that take place just north of Yellowstone Park. Three hunts, known as general season hunts, focus on bulls and occur each autumn. The other hunt, known as the late season hunt, focuses on antlerless elk and occurs during January and February. We calculated a pre-harvest count $\left(\mathrm{N}_{\mathrm{t}}\right)$ by adding, to the count, the number harvested prior to the count. We calculated two harvest statistics. One included the total number of elk harvested each season $\left(\mathrm{TH}_{\mathrm{t}}\right)$. The other excluded elk killed during the fall hunt, which may have less impact on population dynamics because it removes a small portion of the population (2.8\% on average) and consists primarily of bulls. This harvest primarily represents the elk harvest during the late hunt, which occurs during February and March. We denote this statistic as $\mathrm{LH}_{\mathrm{t}}$. In each case, we calculated harvest rate $\left(\mathrm{TH}_{\mathrm{t}}\right.$ and $\left.\mathrm{LH}_{\mathrm{t}}\right)$ as the number of elk harvested divided by $\mathrm{N}_{\mathrm{t}}$. From successive annual values of $\mathrm{N}_{\mathrm{t}}$, we estimated annual population growth rate for year $\mathrm{t}$ as $\mathrm{r}_{\mathrm{t}}=\ln \left(\mathrm{N}_{\mathrm{t}+1}\right)-\ln \left(\mathrm{N}_{\mathrm{t}}\right)$.

\section{Weather data}

We used weather data collected from the Mammoth weather station, which is located on the Northern Range. Specifically, we used mean daily maximum temperature during summer (June-August), mean daily minimum temperature during winter (January-February), cumulative snowfall (October-April, $\mathrm{S}_{\mathrm{t}}$ ), annual precipitation (November-October, $\mathrm{P}_{\mathrm{t}}$ ), and summer precipitation (July) (Table 1). We considered summer precipitation separately because elk may be especially limited by the nutritive quality of summer forage (Merrill and Boyce 1991, Cook et al. 2004). Importantly, summer precipitation and annual precipitation are not well correlated $(\mathrm{R}=0.15, \mathrm{p}=0.35)$. We also used an index of snow water equivalent (i.e. water content of the snow) measured four times during each winter (1 Jan, 1 Feb, 1 Mar and 1 April). Snow water equivalent may indicate winter severity or drought stress. These data were measured in the Northern Range near Lupine Creek and were obtained from Farnes (1996) and P. Farnes and C. Hayden (pers. comm.).

\section{Wolf predation data}

The total number of elk killed by a sample of wolf packs living in the Northern Range, during two 30-day intervals beginning each 15 November and 1 March since 1995 , has been estimated by intensively monitoring the movements and activities of radio-collared wolves 
Table 1. Data pertaining to elk demography and climate for the northern Yellowstone elk herd in Montana and Wyoming. Elk data were obtained from Taper and Gogan (2002), Lemke et al. (1998), and from annual harvest reports (Montana Fish Wildlife and Parks 2004). Climate data were obtained from the Western Regional Climate center (www.wrcc.dri.edu/), Farnes (1996), and P. Farnes and C. Hayden (pers. comm.). The climate data have been normalized to have a mean value of zero and a standard deviation of one

\begin{tabular}{|c|c|c|c|c|c|c|c|c|c|c|}
\hline Year & Elk* & $\begin{array}{c}\text { Elk prior to } \\
\text { harvest } \\
\dagger\end{array}$ & $\begin{array}{c}\text { Late } \\
\text { harvest }\end{array}$ & $\begin{array}{c}\text { Total } \\
\text { harvest }\end{array}$ & $\begin{array}{l}\text { Winter minimum } \\
\text { temperature }\end{array}$ & $\begin{array}{c}\text { Summer } \\
\text { maximum } \\
\text { temperature } \\
* *\end{array}$ & Annual precip. & $\begin{array}{l}\text { Summer } \\
\text { precip. }\end{array}$ & $\begin{array}{c}\text { Annual } \\
\text { Snowfall } \\
\S \S\end{array}$ & $\begin{array}{c}\text { Snow water } \\
\text { equivalent }\end{array}$ \\
\hline $1960-61$ & 8150 & 9609 & - & 1459 & 1.15 & 0.66 & 0.32 & -0.22 & -1.52 & -0.94 \\
\hline $1961-62$ & 5725 & 10469 & - & 4744 & -1.19 & -0.95 & 0.55 & 0.59 & 2.20 & 0.78 \\
\hline $1962-63$ & - & - & - & 1820 & -0.55 & 0.49 & 1.53 & -1.01 & -2.19 & -0.88 \\
\hline $1963-64$ & - & - & - & 1151 & -0.84 & 0.96 & 0.22 & -0.33 & 0.49 & -0.14 \\
\hline $1964-65$ & 4476 & 6380 & - & 1904 & -1.75 & -0.39 & 0.96 & 0.44 & 0.00 & 1.79 \\
\hline $1965-66$ & - & 6534 & - & 1270 & -0.89 & 1.07 & -1.17 & -1.21 & -2.16 & -0.71 \\
\hline $1966-67$ & 3842 & 6534 & - & 2692 & 1.64 & 0.59 & 0.99 & 0.52 & 0.00 & 1.29 \\
\hline $1967-68$ & 3172 & 4272 & - & 1100 & 0.64 & 0.39 & 2.32 & -1.19 & 1.30 & 1.32 \\
\hline $1968-69$ & 4305 & 4355 & - & 50 & -0.32 & -0.29 & 0.46 & -0.32 & -0.25 & 1.27 \\
\hline $1969-70$ & 5543 & 5593 & - & 50 & -0.53 & 0.07 & -0.49 & 0.09 & -0.35 & -0.14 \\
\hline $1970-71$ & 7281 & 7326 & - & 45 & -0.23 & -0.24 & 0.00 & -0.80 & 0.71 & 1.38 \\
\hline $1971-72$ & 8215 & 8290 & - & 75 & 0.53 & -0.79 & 2.36 & 0.06 & 1.93 & 1.60 \\
\hline $1972-73$ & 9981 & 10135 & - & 154 & 0.18 & 0.20 & -0.91 & -0.12 & -0.67 & -0.82 \\
\hline $1973-74$ & 10529 & 10739 & - & 210 & 0.03 & 0.93 & -0.98 & -0.60 & -0.71 & 0.15 \\
\hline $1974-75$ & 12607 & 12754 & - & 147 & -1.17 & 0.49 & -0.31 & 0.39 & 1.24 & 0.09 \\
\hline $1975-76$ & 12014 & 12354 & 1189 & 1529 & 0.08 & 0.66 & 1.27 & 0.48 & 1.27 & 1.38 \\
\hline $1976-77$ & 12828 & 13047 & 0 & 219 & -0.49 & 0.31 & -1.11 & 1.03 & -0.95 & -1.58 \\
\hline $1977-78$ & 12680 & 12941 & 802 & 1063 & 1.72 & 0.01 & -0.76 & -0.29 & 0.00 & 1.36 \\
\hline $1978-79$ & 10838 & 11149 & 31 & 342 & -1.43 & 0.64 & -0.45 & -0.12 & -1.23 & 0.70 \\
\hline 1979-80 & - & - & 467 & 661 & -0.66 & -0.25 & 0.32 & 0.45 & 0.62 & -0.90 \\
\hline $1980-81$ & - & - & 133 & 376 & 0.97 & 0.00 & - & -1.65 & -2.15 & -1.74 \\
\hline $1981-82$ & 16019 & 16363 & 1015 & 1359 & -0.62 & -1.25 & - & -0.03 & 0.19 & -0.08 \\
\hline $1982-83$ & - & - & 1434 & 1881 & 1.67 & -1.31 & - & 2.05 & -0.81 & -0.41 \\
\hline $1983-84$ & - & - & 1657 & 2061 & 0.48 & -0.19 & - & 2.43 & -0.47 & -0.96 \\
\hline $1984-85$ & - & - & 1211 & 1571 & -1.53 & 0.29 & -0.72 & 0.55 & -0.88 & -0.08 \\
\hline $1985-86$ & 16286 & 16742 & 1042 & 1498 & 2.09 & -1.49 & 0.12 & 1.26 & 0.08 & 0.21 \\
\hline $1986-87$ & 17007 & 17901 & 845 & 1739 & 0.32 & -1.59 & -0.58 & 2.51 & -1.89 & -1.57 \\
\hline $1987-88$ & 18913 & 19272 & 220 & 579 & -0.65 & 0.85 & -1.39 & -0.57 & -0.68 & -1.47 \\
\hline $1988-89$ & 16536 & 17023 & 2409 & 2896 & -1.14 & 0.93 & 0.58 & -0.22 & 0.80 & 0.06 \\
\hline $1989-90$ & 14829 & 15644 & 484 & 1299 & 0.40 & -0.04 & -0.83 & -1.22 & -0.56 & 0.33 \\
\hline $1990-91$ & 12027 & 12335 & 697 & 1005 & 0.84 & 0.51 & 0.05 & -0.72 & 0.62 & -0.80 \\
\hline $1991-92$ & 12859 & 15587 & 1787 & 4515 & 1.67 & -2.17 & 0.21 & 0.45 & -0.29 & -0.18 \\
\hline $1992-93$ & 17585 & 18066 & 1574 & 2055 & -0.62 & -3.16 & 0.97 & 1.04 & 0.25 & 0.02 \\
\hline $1993-94$ & 19045 & 19299 & 273 & 527 & 0.68 & -0.35 & -0.54 & 0.10 & -0.34 & -0.67 \\
\hline $1994-95$ & 16791 ฯ & 17290 & 2039 & 2538 & 0.72 & -1.06 & 0.49 & 0.68 & 0.42 & -0.10 \\
\hline $1995-96$ & 15091 ๑ & 15397 & 1400 & 1706 & -0.84 & 0.55 & -0.32 & -0.57 & 1.26 & 0.43 \\
\hline $1996-97$ & 13391 & 14246 & 2465 & 3320 & -0.19 & -0.75 & 1.64 & 1.88 & 0.70 & 2.11 \\
\hline $1997-98$ & 11692 & 12025 & 1273 & 1606 & 0.75 & 0.96 & -0.94 & -0.65 & -0.38 & 0.00 \\
\hline $1998-99$ & 11742 & 12075 & 1626 & 1959 & 0.51 & 0.22 & 0.04 & -1.05 & 1.01 & 0.93 \\
\hline $1999-00$ & 14538 & 14682 & 940 & 1084 & 0.83 & 1.08 & -0.33 & -1.17 & -0.26 & -0.57 \\
\hline $2000-01$ & 13400 & 13673 & 1221 & 1494 & -0.74 & 0.43 & -1.78 & 0.03 & -0.11 & -1.31 \\
\hline
\end{tabular}




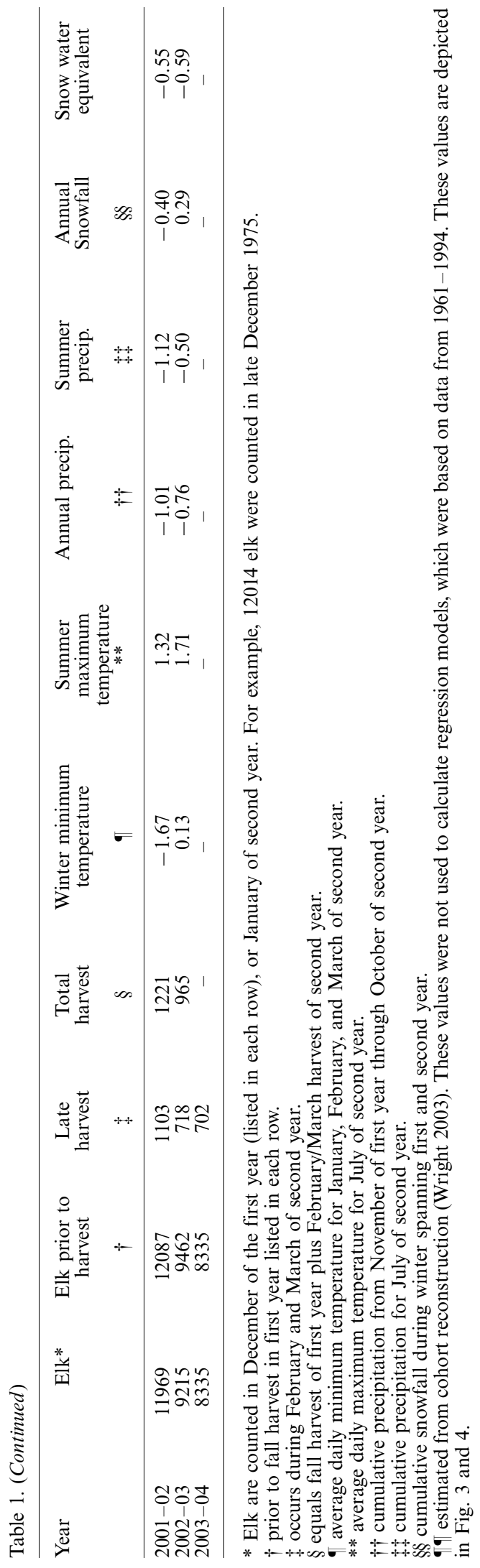

from the ground and from aircraft (Smith et al. 2004, Table 2). The total number of elk killed annually by wolves may be extrapolated by: i) assuming that monitored and unmonitored packs in the North Range kill at that same rates, and ii) assuming that kill rates during November and February are representative of kill rates during that winter (November through April) and by assuming that summer kill rates (May through October) are well represented by multiplying winter kill rates by 0.70 (Messier 1994). From these numbers we estimated annual wolf predation rate $\left(\mathrm{W}_{\mathrm{t}}\right)$ as the extrapolated number of elk killed divided by the number of elk in the population. We also assess the consequences of the above mentioned assumptions.

\section{Model selection and assessment}

Prior to wolf reintroduction

We estimated parameters for several multiple linear regression models. The dependent variable for these models was $r_{t}$, for $t=1961-1994$. Estimated models were selected by means of the stepwise regression algorithm. The candidate independent variables included: $\mathrm{N}_{\mathrm{t}}, \ln \left(\mathrm{N}_{\mathrm{t}}\right), \mathrm{TH}_{\mathrm{t}}, \mathrm{LH}_{\mathrm{t}}$, and the weather variables described in the previous section. We also considered lagged terms and squared terms for each of the variables.

During the 1980s, the range area occupied by northern Yellowstone elk expanded by approximately $40 \%$ (Lemke et al. 1998). Because population dynamics are often predicted from density, and because density is affected by area occupied by the population, it is important to explicitly assess the effect of the range expansion. To do this, we considered indicator variables that would allow for different intercepts $\left(\mathrm{IA}_{t}\right)$ and abundance coefficients $\left(\mathrm{IB}_{\mathrm{t}}\right)$ for the time periods prior to and after 1980. For example, the structure of a model with different intercepts and abundance coefficients would be: $r_{t}=\alpha_{0}+$ $\alpha_{I A} I_{t}+\alpha_{N} N t+\alpha_{I B} I B_{t}$, where $I_{t}$ is zero for $t<1980$ and one for $\mathrm{t}>1980$; and $\mathrm{IB}_{\mathrm{t}}$ is zero for $\mathrm{t}<1980$ and $\mathrm{N}_{\mathrm{t}}$ for $t>1980$. Either a different intercept or slope would

Table 2. The numbers of packs in the Northern Range of Yellowstone National and the documented number of elk killed by monitored packs during March and November between 1995 and 2003. Each year three packs were monitored.

\begin{tabular}{cccc}
\hline Year & No. of packs & \multicolumn{2}{c}{ No. of elk killed by monitored packs } \\
\cline { 2 - 4 } & & March & November \\
\hline 1995 & 3 & 34 & 12 \\
1996 & 4 & 38 & 32 \\
1997 & 4 & 43 & 26 \\
1998 & 4 & 56 & 24 \\
1999 & 4 & 39 & 27 \\
2000 & 5 & 37 & 29 \\
2001 & 6 & 25 & 28 \\
2002 & 9 & 35 & 33 \\
2003 & 10 & 32 & \\
\hline
\end{tabular}


correspond to a different equilibrium size (carrying capacity, Royama 1992).

To compare the performance of each model, we used $\mathrm{R}^{2}$ and information-theoretic statistics (Burnham and Anderson 1998, Anderson et al. 2000). More specifically, we calculated each model's $\mathrm{AIC}_{\mathrm{C}}$ (Akaike's information criterion, corrected for small sample size): $\mathrm{AIC}_{\mathrm{C}}=$ $-[2 \ln (\mathrm{L}(\theta \mid$ data $))]+2 \mathrm{~K}+2 \mathrm{~K}(\mathrm{~K}+1) /(\mathrm{N}-\mathrm{K}-1), \quad$ where $\ln (\mathrm{L}(\theta \mid$ data $)$ is the value of the maximized log-likelihood over the unknown parameters, given the model and the data, $\mathrm{K}$ is the number of model parameters, and $\mathrm{N}$ is the sample size. The first term in the expression for $\mathrm{AIC}_{\mathrm{C}}$ represents a measure of the model's fit, the second term a penalty for each parameter in the model, and the third term a correction for small sample size. $\mathrm{AIC}_{\mathrm{C}}$ relies on principles of parsimony and information theory to estimate the relative distance between a model and the underlying process that created the observed data.

We also calculated $\Delta \mathrm{AIC}_{\mathrm{C}}$, which equals the $\mathrm{AIC}_{\mathrm{C}}$ for the model of interest minus the smallest $\mathrm{AIC}_{\mathrm{C}}$ for the set of models being considered. The best model has a $\Delta \mathrm{AIC}_{\mathrm{C}}$ of zero. Models with $\Delta \mathrm{AIC}_{\mathrm{C}}<2$ are considered worthy of consideration (Burnham and Anderson 1998). From $\mathrm{AIC}_{\mathrm{C}}$ values we also calculated the $\mathrm{AIC}_{\mathrm{C}}$ weight of each model $\mathrm{i}\left(\mathrm{w}_{\mathrm{i}}\right)$ (Anderson et al. 2000: p. 918 provide an expression for $\mathrm{w}_{\mathrm{i}}$ ). The ratio $\mathrm{w}_{\mathrm{i}}: \mathrm{w}_{\mathrm{j}}$ estimates how many times more support the data provide for model $\mathrm{i}$ than model $\mathrm{j}$.

\section{Results}

\section{Properties of the models}

Four of the models estimated by the stepwise regression algorithm (Table 3, Fig. 1) performed reasonably well with respect to absolute predictability (i.e. $\mathrm{R}^{2}>0.5$ ), including only variables with small $\mathrm{p}$-values, and small values of $\Delta \mathrm{AIC}_{\mathrm{C}}$ (i.e. $<2.0$ ). The stepwise regression algorithm did not select any models which included $\ln \left(\mathrm{N}_{\mathrm{t}}\right)$, nor did it select models with lagged terms (Taper and Gogan 2002). For the best performing models, the residuals were not autocorrelated, nor did plots of predictor variables versus residuals suggest that any of the models were failing to capture any significant nonlinearities. We do not doubt that the system may contain nonlinearities, but claim only that linear relationships adequately fit the observed data over the range of observed parameter space (Vucetich and Peterson 2004). None of the best performing models exhibited multicolinearity, nor were they excessively influenced by individual observations.

Harvest rate (excluding the fall harvest) appears as a predictor variable in each model (Table 3). The contribution of harvest rate to explaining the variation in elk growth rate can be estimated by multiplying the standardized regression coefficient for harvest times that correlation coefficient between $\mathrm{LH}_{\mathrm{t}}$ and $\mathrm{r}_{\mathrm{t}}$ (Schumacker and Lomax 1996). We calculated this statistic for each of the four best models, and calculated an average contribution of $\mathrm{LH}_{\mathrm{t}}$, weighted by each model's $\mathrm{AIC}_{\mathrm{C}}$ weight. According to this calculation, harvest rate accounts for $47 \%$ of the observed annual variation in elk population growth rate for the period 1961-1995.

The regression coefficient for $\mathrm{LH}_{t}\left(\alpha_{\mathrm{H}}\right)$ is a measure of the degree to which harvest is additive. If $\alpha_{\mathrm{H}}=-1$, then harvest is purely additive. That is, an increase of 0.01 in $\mathrm{LH}_{\mathrm{t}}$ would correspond with a decrease in annual growth rate of 0.01 . We calculated the weighted average value for estimates of $\alpha_{\mathrm{H}}$, where the average is taken across all models with $\Delta \mathrm{AIC}_{\mathrm{C}}<2$, and each model estimate is weighted by the model's AICc weight, which indicates

Table 3. Comparison of models selected by stepwise regression algorithm.

\begin{tabular}{|c|c|c|c|c|c|}
\hline Predictor variables* & $\underset{\dagger}{\mathrm{AIC}_{\mathrm{c}}}$ & $\underset{+}{\Delta \mathrm{AIC}_{\mathrm{c}}}$ & $\mathrm{W} \S$ & $\mathrm{R}^{2}-$ & $\begin{array}{l}\text { Projected average } \\
\mathrm{r}_{\mathrm{t}}^{* *}\end{array}$ \\
\hline $\mathrm{LH}$ & -78.7 & 5.5 & 0.02 & 0.27 & - \\
\hline $\mathrm{LH}(<0.01), \mathrm{P}(0.01)$ & -83.5 & 0.8 & $0.20(0.22)$ & 0.49 & -0.054 \\
\hline $\mathrm{LH}(<0.01), \mathrm{P}(<0.01), \mathrm{S}(0.07)$ & -84.1 & 0.1 & $0.27(0.30)$ & 0.57 & -0.107 \\
\hline $\mathrm{LH}(<0.01), \mathrm{P}(<0.01), \mathrm{S}(0.06), \mathrm{N}(0.08)$ & -84.2 & 0.0 & $0.29(0.32)$ & 0.64 & -0.097 \\
\hline $\mathrm{LH}(<0.01), \mathrm{P}(0.01), \mathrm{S}(0.09), \mathrm{N}(0.03), \mathrm{IA}(0.14)$ & -82.9 & 1.3 & $0.15(0.16)$ & 0.69 & -0.047 \\
\hline $\mathrm{LH}, \mathrm{P}, \mathrm{S}, \mathrm{N}, \mathrm{IA}, \mathrm{IB}$ & -81.5 & 2.7 & 0.07 & 0.74 & - \\
\hline LH, P, S, N, IA, IB, S(lag) & -77.8 & 6.4 & 0.01 & 0.76 & - \\
\hline
\end{tabular}

*The symbols are: $\mathrm{LH}=$ late harvest rate, $\mathrm{P}=$ annual precipitation, $\mathrm{S}=$ cumulative snowfall, $\mathrm{N}=$ abundance, $\mathrm{IA}=$ indicator variable for intercept (see text), IB = indicator variable of abundance coefficient (see text), $\mathrm{S}(\mathrm{lag})=$ cumulative snowfall during previous winter. Numbers in parenthesis under predictor variables are p-values for the four best-performing models.

** Projected average $r_{t}$ is the average growth rate for values of $\mathrm{N}_{t}$ projected over the period between 1995 and 2004 (Fig. 3). Projected averages were not calculated for models with $\Delta \mathrm{AIC}_{\mathrm{C}}>2.0$. For reference, the observed annual decline was -0.081 .

$\uparrow \mathrm{AIC}_{\mathrm{C}}$ is Akaike's information criterion, corrected for small sample size.

$\sharp \triangle \mathrm{AIC}_{\mathrm{C}}$ is $\mathrm{AIC}_{\mathrm{C}}$ for the model of interest minus the smallest $\mathrm{AIC}_{\mathrm{C}}$ for the set of models being considered. We only considered models with $\triangle \mathrm{AIC} C 2$.

$\S \mathrm{W}$ is the $\mathrm{AIC}_{\mathrm{C}}$ weight of each model. The ratio of one model's weight to another estimates how many times more support the data provide for that model over the other. Numbers in paranthesis under $\mathrm{W}$ are $\mathrm{AIC}_{\mathrm{C}}$ weights computed relative to just the four best performing models.

T $\mathrm{R}^{2}$ is the proportion of total variation explained by each model. 


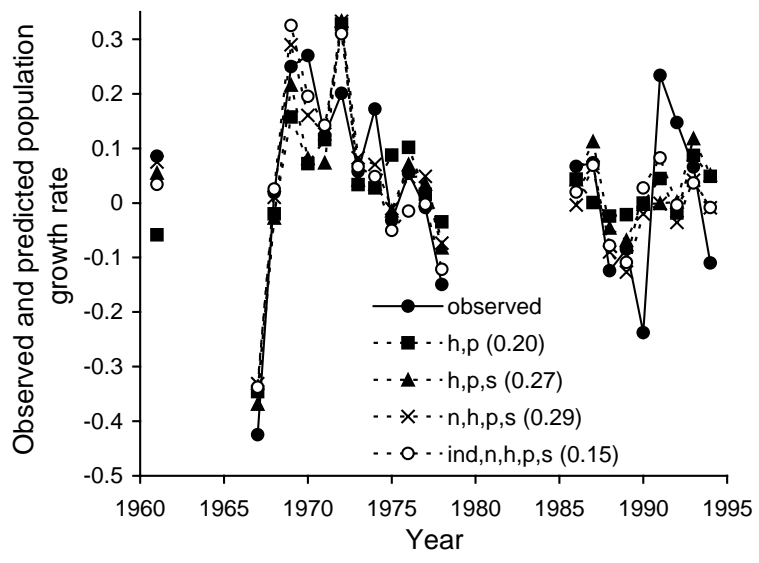

Fig. 1. Observed and predicted population growth rates for northern Yellowstone elk prior to wolf reintroduction, 19611994. Each set of predictions corresponds to each of four bestperforming models depicted in Table 3 (i.e. with $\Delta \mathrm{AIC}_{\mathrm{C}}<2.0$ ). Numbers in parentheses are $\mathrm{AIC}_{\mathrm{C}}$ weights (W in Table 3) for each model.

the model's likelihood, relative to other the models (Anderson et al. 2000). The weighted average value of $\alpha_{\mathrm{H}}$ is -1.5 , which may indicate that harvest is superadditive (Discussion). We also quantified uncertainty in $\alpha_{H}$ by examining the distribution of bootstrap estimates of $\alpha_{\mathrm{H}}$ (for the model with the best performing structure in Table 3).

The $95 \%$ confidence interval for $\alpha_{H}$ is $[-2.1,-0.32]$, the $80 \%$ confidence interval for $\alpha_{\mathrm{H}}$ is $[-2.0,-0.72]$, and the $50 \%$ confidence interval for $\alpha_{H}$ is $[-1.8,-1.2]$. The apparent super-additivity of the harvest may be explained by the fact that most elk $(70 \%)$ taken in the harvest were pregnant (Lemke 2003).

To better understand the importance of each predictor variable, we also calculated the standardized regression coefficients for each of four best performing models. Standardized regression coefficients represent the change in the response variable $\left(\mathrm{r}_{\mathrm{t}}\right.$; measured in units of standard deviation of the response variable) for every unit change in a particular predictor variable (measured in units of standard deviation for that predictor variable). Standardized regression coefficients allow one to compare coefficients for predictor variables that are measured on different scales (e.g. abundance and precipitation). We calculated the weighted average value for each standardized regression coefficient, where the average is taken across all models with $\Delta \mathrm{AIC}_{\mathrm{C}}<2$, and each model estimate is weighted by the model's $\mathrm{AIC}_{\mathrm{C}}$ weight (Fig. 2).

\section{Model projections}

We projected growth rates and abundances from 19952004 on the basis of the best performing models in Table 3. These predictions were calculated as:

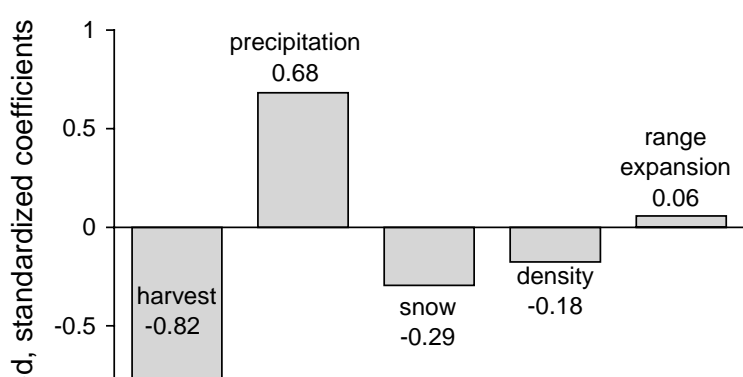

Predictor variable

Fig. 2. The weighted, standardized regression coefficients for each predictor variable included in the four best-performing models depicted in Table 3 (i.e. with $\Delta \mathrm{AIC}_{\mathrm{c}}<2.0$ ). Each value is a weighted average of the standardized coefficients for each of the models, where the weight is the $\mathrm{AIC}_{\mathrm{c}}$ weight ( $\mathrm{W}$ in Table 3) of each corresponding model. The relative influence of each variable may be assessed by comparing these coefficients because standardized regression coefficients reflect how many standard deviation units the response variable changes for every standard deviation unit change in the corresponding predictor variable.

$r_{t}=f\left(N_{t}, H_{t}, C_{t}\right)$ for $t=1995$

$r_{t}=f\left(\hat{N}_{t}, H_{t}, C_{t}\right)$ for $t>1995$

where $f()$ represents one of the models in Table $3, C_{t}$ represents a set of climate variables corresponding to one of the models in Table 3, and $\hat{\mathrm{N}}_{\mathrm{t}}=\exp \left(\ln \left(\mathrm{N}_{\mathrm{t}-1}^{*}\right)+\mathrm{r}_{\mathrm{t}}\right)$, where $\mathrm{N}_{\mathrm{t}-1}^{*}=17290$ for $\mathrm{t}-1=1995$ (Table 1 ) or $\mathrm{N}_{\mathrm{t}-1}^{*}=$ $\hat{\mathrm{N}}_{\mathrm{t}-1}$ for $\mathrm{t}-1>1995$.

Projected values of elk abundance tend to decline from 1995 to 2004 for each of the models that performed reasonably well (Fig. 3). We calculated the weighted average value for estimates of projected $\mathrm{N}_{\mathrm{t}}$, where the

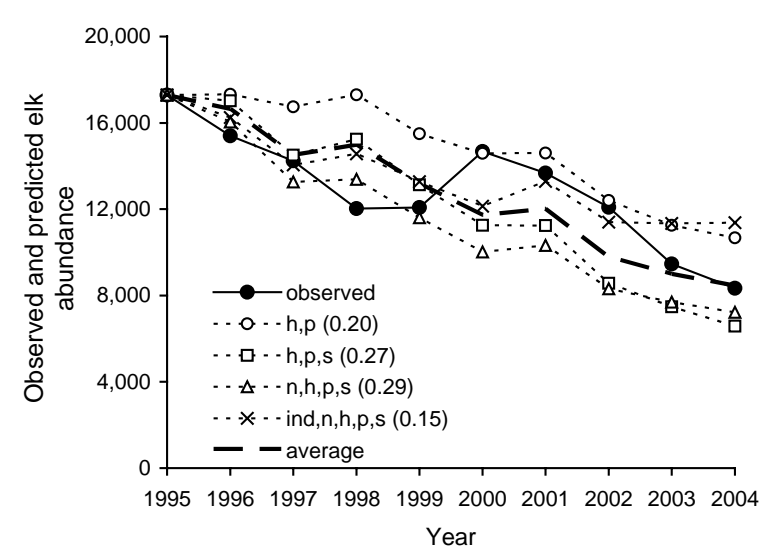

Fig. 3. Observed and projected population abundances for northern Yellowstone elk after wolf reintroduction, 19952004. Each set of predictions corresponds to each of the four best-performing models depicted in Table 3 (i.e. with $\Delta \mathrm{AIC}_{\mathrm{c}}<$ 2.0). The numbers in parentheses are $\mathrm{AIC}_{\mathrm{c}}$ weights (W in Table 3 ) for each model. 
average is taken across all models with $\Delta \mathrm{AIC}_{\mathrm{C}}<2$, and each model estimate is weighted by the model's $\mathrm{AIC}_{\mathrm{C}}$ weight. The series of weighted averages declined, with an average annual growth rate of -0.079 from 1995 to 2004. The observed average annual rate of decline was -0.081 for the same period. Thus, harvest, climate, and density dependence appear able to account for most $(98 \%=-0.079 /-0.081)$ of the observed decline.

To further explore the influence of climate and harvesting on the observed decline, we projected the best performing model under three hypothetical scenarios for the period 1995-2004 (Fig. 4): 1) low harvest and realized (e.g. drought) climate; 2) realized harvest and average climate; and 3) low harvest and average climate. Low harvest corresponds to a $4.5 \%$ harvest rate each year. This value is half of the actual average harvest rate during this time period (1995-2003). These scenarios suggest that both climate and harvest contributed importantly to the decline since 1995 . Had either the climate been milder or had the harvest been lighter, the population would have declined only slightly. The slight decline in either case would have been attributable to density dependence.

There is uncertainty in the actual average rate of elk decline (based on the elk counts, column 3 in Table 1). Moreover, the projected rates of decline (Fig. 3, which is based on models in Table 3) do not account for uncertainty or the influence of environmental stochasticity. To quantify these uncertainties and environmental stochasticity and to better appreciate how they affect interpretation of the projected values of $\mathrm{N}_{t}$, we calculated and compared estimated probability distributions for each average rate of decline. First, we estimated the probability distribution for rate of decline in elk counts by calculating a normal probability distribution with a

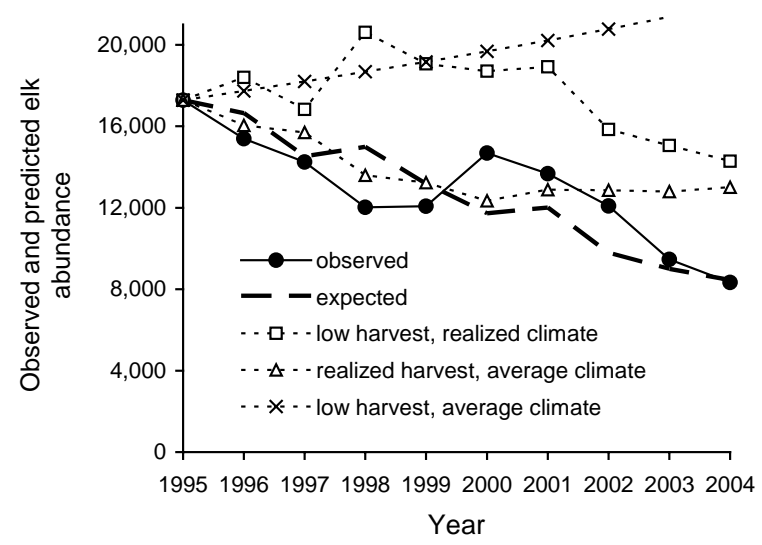

Fig. 4. Observed and projected population abundances for northern Yellowstone elk after wolf reintroduction (19952004) under hypothetical scenarios, entailing lower rates of harvest and (or) average climatic conditions. Low late harvest rates correspond to $\mathrm{LH}_{\mathrm{t}}=0.05$ for $\mathrm{t}=1995$ to 2004 , which is half the average rate observed during this period.

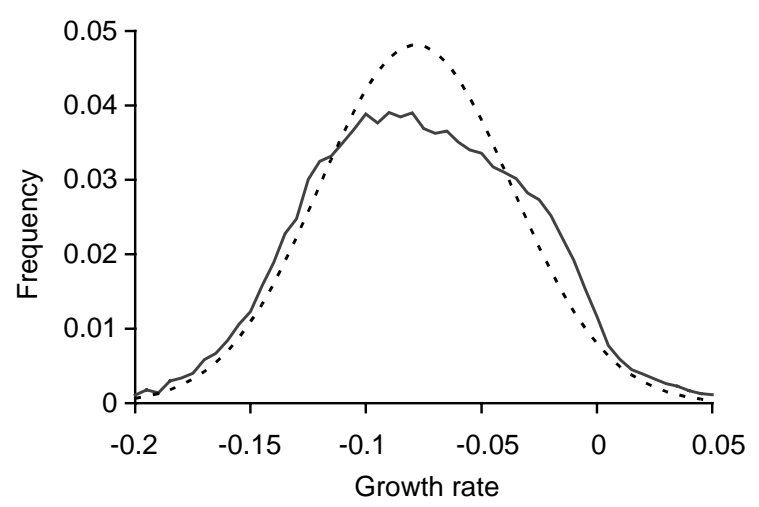

Fig. 5. Estimated probability distributions for the average annual rate of population decline since wolf reintroduction (1995-2004) based on temporal variation in observed elk counts (solid line) and on projected models (Table 3) parameterized from 20000 bootstrap samples of the original data, prior to wolf reintroduction (dotted line).

mean value of -0.081 (the estimated average rate of decline) and a standard deviation of 0.041 , which is the estimated standard error for the observed average rate of decline from 1995 to 2004 (solid curve in Fig. 5). Second, we estimated the probability distribution for rate of decline in projected values of $\mathrm{N}_{t}$ (i.e. Fig. 3) by projecting values of $\mathrm{N}_{\mathrm{t}}$ based on models estimated from bootstrap samples of the data (dotted curves in Fig. 5). More specifically: 1) we created numerous bootstrap samples from which we estimated regression coefficients for models with structure corresponding to each of the four best performing models in Table 3, and 2) on the basis of each set of bootstrapped regression coefficients (including the error terms which represent environmental stochasticity) we calculated average growth rates from trajectories of projected values of $\mathrm{N}_{\mathrm{t}}$ (for $\mathrm{t}=1995$ to 2004). We did this 5000 times for each of the four model structures. This generated four sets of 5000 averaged growth rates. Next we generated a single frequency distribution from these four sets of values, where the contribution of each set was weighted according to the AICc weight for each corresponding model. We did this by counting, for each set, the number of growth rates falling within each of 50 equal size intervals between -0.20 to 0.05 (Fig. 5). The number in each category was then multiplied by the corresponding $\mathrm{AIC}_{\mathrm{C}}$ weight. Because the bootstrap distribution and the normal distribution largely overlap (Fig. 5), the observed decline in elk counts is not significantly different from the projected decline in elk numbers.

Context for these results is provided by examining patterns of harvest and climate between 1995 and 2003 (Table 1). Specifically, average harvest rate for the late harvest between 1995 and $2003(10.4 \%)$ was 2.7 times greater than average harvest rate between 1970 and 1994 and $67 \%$ higher than the average rate between 1986 and 
1994. Annual precipitation had been below average in six (of nine) years between 1995 and 2003. Some of these years were characterized by extremely low precipitation (e.g. 1998, 2001 and 2002, Table 1). Average cumulative snowfall for the years between 1995 and 2003, has also been slightly above that of previous years (e.g. 1995-96, 1996-97 and 1999-2000). The projected decline is associated with increased harvest and climate conditions that had been more severe than in previous years.

\section{Wolf predation}

To assess, as directly as possible, how wolf predation may have affected elk population dynamics, we first calculated residuals for each of the four best performing models (Table 3 ) by subtracting the estimated number of elk $\left(\mathrm{N}_{\mathrm{t}}\right)$ from the projected number $\left(\hat{\mathrm{N}}_{\mathrm{t}}\right)$ for each year between 1995 and 2004. Then we regressed predation rate $\left(\mathrm{W}_{\mathrm{t}}\right)$ (which were calculated by methods described in wolf predation data and from data in Table 2) on the residuals to quantify the influence of estimated annual kill rate on elk growth rate. The slope of this regression estimates the degree to which wolf predation is additive, given the influence of harvest, precipitation, snowfall, and range expansion predicted by each of the best models. More specifically, the slope indicates by how much elk population growth rate would decline for every unit change in predation rate.

Recall, predation rate was extrapolated by assuming that summer kill rate is $70 \%$ of winter kill rate. Although this assumed relationship seems reasonable, data supporting any estimate are very limited. Because the relationship between summer and winter kill rates is not well understood, the estimated slopes could be biased to the extent that we over- or underestimate summer kill rates. However, the significance (i.e. p-values) for the slopes should not be biased if summer and winter kill rates are well correlated, or if inferences are limited to assessing the influence of winter predation rates on elk population dynamics. Under such circumstances estimated winter predation would be a linearly-transformed index of the total annual predation rate.

For each of the four best models, the p-value for the significance of the slope was large: $p=0.74$ for the model including harvest and precipitation (i.e. the model in Table 3 with an $\left.\Delta \mathrm{AIC}_{\mathrm{C}}=0.8\right), \mathrm{p}=0.85$ for the model including harvest, precipitation, and snowfall $\Delta \mathrm{AIC}_{\mathrm{C}}=$ $0.1), \mathrm{p}=0.48$ for the model including harvest, precipitation, snowfall, and density $\Delta \mathrm{AIC}_{\mathrm{C}}=0$ ), and $\mathrm{p}=0.35$ for the model including harvest, precipitation, snowfall, density, and an indicator variable for the intercept $\left.\Delta \mathrm{AIC}_{\mathrm{C}}=1.3\right)$. Confidence intervals $(95 \%)$ for the slopes of each model were also large: $[-4.6,3.4]$ for the model with $\Delta \mathrm{AIC}_{\mathrm{C}}=0.8,[-5.3,4.5]$ for the model with
$\Delta \mathrm{AIC}_{\mathrm{C}}=0.1,[-6.2,3.2]$ for the model with $\Delta \mathrm{AIC}_{\mathrm{C}}=$ 0 , and $[-6.4,2.6]$ for the model with $\Delta \mathrm{AIC}_{\mathrm{C}}=1.3$. This more direct examination also fails to show that wolf predation had been an important influence on elk population dynamics.

One might also consider assessing the influence of predation by comparing the performance of a pair of models based on data from 1961 to 2004, where one model includes harvest, climate, and elk density and the other model includes these predictors as well as predation rate, where predation rate is calculated from Table 2 for years 1995-2003 and is zero for years prior to 1995 . When this approach is taken, the model without wolf predation receives five times as much support as the model with wolf predation (on the basis of $\mathrm{AIC}_{\mathrm{C}}$ weights), and the p-value for the wolf predation coefficient is 0.76 .

\section{Discussion}

Some managers and segments of the general public express concern over a strong belief that northern Yellowstone elk have been declining (from 1995 to 2004) and that the decline is importantly attributable to wolf predation. Our analysis (Fig. 3, 5) indicates that there is greater justification for believing that harvest rate and severe climate, together, account for at least much of the decline. During this time, harvest and climate conditions were more severe than in previous years (Table 1). To the extent that harvest and climate largely account for the decline in elk abundance (from 1995-2004), wolf predation would have been either numerically minor and (or) substantially compensatory (not additive).

Portions of our analysis are based on some simplifying assumptions about wolf predation. We took annual predation rates to be a linear function of predation rates estimated during March and November. Virtually all assessments of wolf predation are similarly limited (Messier 1994). These assumptions do not affect the claim that elk decline may be explained without invoking wolf predation (Fig. 3). Otherwise, claims concerning the regression and residual analysis require assuming only that kill rates in March and November are correlated with kill rates in other portions of the year (e.g. years with higher than average kill rates in March and November also have higher than average kill rates at other times during the same year). Because our calculations suggest that the average annual predation rate between 1995 and 2003 was relatively low (i.e. 0.05), we would have to have underestimated unmeasured kill rate by a substantial amount for the true annual predation rates to have been high (say 0.10 , which is the average rate of the late harvest). Regardless, concerns about the true nature of annual predation rate represent good 
reason to focus on the observation that elk decline can be explained without any reference to wolf predation (i.e. Fig. 3).

The logic of our analysis (which is based on dynamics in the absence of predation; i.e. Fig. 1) and interpretation is not affected by the possibility that predation would affect or is affected by age structure. Nevertheless, our analysis does not explicitly account for the influence of age structure on density dependence. Given the life history of elk and the assessment by Lande et al. (2003 p.72), we expect annual and total density dependence (sensu Lande et al. 2002) to be weaker than the direct density dependence (i.e. see best performing model in Table 3). For this reason, and because our assessment suggests that direct density dependence is weak, a more precise accounting of density dependence would not likely affect our conclusion that harvest and climate are more important processes.

Several independent observations further justify considering wolf predation to have been substantially compensatory and suggest some of the mechanisms by which compensation may have been occurring. Generally, wolves in YNP and elsewhere have tended to prey on elk with apparently high risk of mortality from other causes (Peterson 1977). More specifically, in YNP: 1) virtually all elk killed by wolves in late winter (March) have exhibited signs of poor nutrition (i.e. low fat content in the bone marrow of femurs; YNP unpubl.; Cook et al. 2001); 2) wolves have tended to select calves and elk greater than nine years of age (Smith et al. 2004) - age classes that tend to elevated mortality rates (Loison et al. 1999), even in the absence of wolf predation; and 3) temporal variation (i.e. standard deviation) in elk killed appears to be two to three times greater for calves, bulls, or old cow ( $>$ nine years) than for prime-aged cows $(\mathrm{p}=0.01$ for kills/month; $\mathrm{p}<0.01$ for kills/wolf/month; these p-values are for a test for equality of variances). Although the relevance of this last observation requires further analysis, superficially, it may indicate compensatory predation insomuch as predation rate varies with the availability of elk characterized by low reproductive value and sensitivity (to population growth rate, sensu Caswell 2001).

For additional context, it is useful to recognize that: 1) northern Yellowstone elk are distinctive because they are preyed upon by more predator species than most other elk populations (i.e. humans, wolves, coyotes, cougars, black bears, and grizzly bears; Smith et al. 2003); and 2) since the mid-1980s the abundance of cougars and grizzly bears has also increased (Murphy 1998, Schwartz and Haroldson 2003).

Our analysis suggests that human harvest may have been super-additive. That is, for every one percent increase in harvest rate the population growth rate declines by more than one percent (i.e. 1.55 with $80 \%$ confidence intervals of $[-2.0 \%,-0.7 \%])$. This could reflect both direct and indirect effects of harvest. Alternatively, harvest rates could be correlated with some factor that also tends to reduce population growth rate. Perhaps, for example, harvest and winter severity each reduce population growth rate, and harvest rates tends to be greater in more severe winters. This is plausible because elk mobility is more restricted during sever winters and more easily found by hunters. This possibility is further supported by the positive correlation between cumulative annual snowfall and the late harvest rate $\left(\mathrm{LH}_{\mathrm{t}} ; \mathrm{R}=0.48, \mathrm{p}=0.01\right)$. This correlation does not however imply that the effect of harvest is misconstrued for what is really the effect of cumulative annual snow. This is so because the best performing model (Table 3) with elk density, snow, precipitation, and harvest performs much better compared to the model with only elk density, snow, and precipitation (i.e. $\mathrm{R}^{2}=$ $\left.0.08, \Delta \mathrm{AIC}_{\mathrm{C}}=17\right)$. Models with an interaction term for harvest and snow did not outperform models without this interaction term. More generally, it is not surprising that human harvest would be more additive than wolf predation, because whereas wolves are highly selective for elk in vulnerable age classes, human hunters show no such selection and are more likely to kill prime-aged elk (Wright 2003).

Great value seems to be placed on considering the northern Yellowstone elk herd to be naturally regulated (Coughenhour and Singer 1996, Singer et al. 1998, Huff and Varley 1999, National Research Council 2002, Soulé et al. 2003). However, unless human harvest is considered a natural process, it seems unreasonable to consider the northern Yellowstone elk herd naturally regulated, given that about half of the variation in annual growth rate is attributable to annual variation in harvest rate. If the management goal of the late hunt is to reduce elk abundance for the purpose of increasing the standing biomass of plant species consumed by elk (Lemke 2003), then this analysis indicates that the harvest has been effective in its proximate goal of reducing the abundance of northern Yellowstone elk. More serious consideration should be given to appreciating the effect of human elk harvest on wolf population dynamics.

Another independent observation highlights the apparent role of drought in the recent elk decline (1995-2004). Although ungulate starvation is common near the end of severe winters (i.e. long periods of deep snow which limit mobility and access to forage, e.g. 1996-97), elk starvation is not typically associated with mild winters. Nevertheless, elk starvation was documented in late winter 2003-04, which was mild but preceded by several years of low annual precipitation. Elk may have had elevated risk of starvation even during the mild winter of 2003-04 because forage conditions during the previous summer were poor due to low annual precipitation (Cook et al. 2004). Previous analyses have indicated that precipitation has been an important predictor of elk 
population growth rate (Coughenhour and Singer 1996, Taper and Gogan 2002, Wang et al. 2002).

That predation may have been substantially compensatory or numerically unimportant, does not indicate that wolf predation on elk will be compensatory in the future. Specifically, wolf predation might be more additive for higher rates of predation and (or) under climate conditions that are more favorable to elk. Experimental studies have shown that the extent to which predation or harvest is additive with other sources of mortality depends on time-varying circumstances, such as abundance of food (Floyd 1995, Reid et al. 1995, Oedekoven and Joern 2000, Tveraa et al. 2003). These considerations may indicate why the effects of predator introductions on prey populations seem so varied (Ebenhard 1988, Schmitz et al. 2000). Though human harvesting can be largely compensatory under a wide range of circumstances (Boyce et al. 1999), it is not always (Pederson et al. 2004, Williams et al. 2004, this study). Much more empirical and theoretical insight are required to adequately understand the extent to and circumstances under which harvest and predation are additive to other causes of mortality.

Generally, the influence of predation on prey may be assessed from a variety of perspectives. Common perspectives include assessing kill rate (Vucetich et al. 2002), cause-specific rates of mortality among various age classes of prey (Ballard et al. 2001), and prey abundance in relation to other relevant covariates, such as predator density (Arditi and Ginzburg 1989, Messier 1994). Kill rate assessment, for example, represents a highly mechanistic, but also a highly reductive, perspective. It is reductive in the sense that one assumes prey dynamics may be understood by re-assembling constituent predictors of temporal fluctuation in abundance that are studied separately. In this context, predation may be examined by estimating the functional and numerical responses and then relating them to population dynamics according to Lotka-Volterra theory. In contrast, the perspective taken here (i.e. time series analysis of prey abundance and relevant covariates) is more holistic, but also less mechanistic. This perspective is less mechanistic in the sense that many detailed mechanisms (e.g. functional and numerical responses) are subsumed. This perspective is more holistic in the sense used by philosophers of science (Rosenburg 2000, Lange 2004). That is, it focuses directly on the phenomena of interest; i.e. how factors like drought, harvest and predation affect abundance. This valuable perspective (i.e. that entailing time series analyses of abundance) is increasingly common (Jonzén et al. 2002, 2005, Vucetich and Peterson 2004). Because these and other perspectives each have merits and limitations, it is important to consider various perspectives with a pluralistic attitude. In a significant sense, the perspective is as important as the conclusion. In this case, one may be more impressed by the uncertainty of understanding elk dynamics than by the claim that one is well justified in believing that wolf predation does not explain the population decline. Regardless, the conclusion (whatever it may be) is as important as knowing what can and cannot be said from a legitimate perspective, which is in this case time series analysis of elk abundance.

Acknowledgements - We thank L. Adams, R. Garrott, L. D. Mech, R. O. Peterson and P. J. White for valuable comments and dialogue, and D. Guernsey for technical assistance. We thank the Northern Yellowstone Cooperative Wildlife working group for collecting data on elk demography, and P. Farnes and C. Hayden for sharing data on snow conditions. This study was possible because of the visiting scholar program sponsored by the wolf project of Yellowstone National Park. We thank U.S. National Science Foundation (DEB-9903671 and DEB0424562) for support. The content of article does not necessarily reflect the views of the National Science Foundation or the National Park Service.

\section{References}

Anderson, D. R., Burnham, K. P. and Thompson, W. L. 2000. Null hypothesis testing: problems, prevalence, and an alternative. - J. Wildl. Manage. 64: 912-923.

Arditi, R. and Ginzburg, L. R. 1989. Coupling in predator-prey dynamics - ratio dependence. - J. Theor. Biol. 139: $311-$ 326.

Ballard, W. B., Lutz, D., Keegan, T. W. et al. 2001. Deerpredator relationships: a review of recent North American studies with emphasis on mule and black-tailed deer. - Wildl. Soc. Bull. 29: 99-115.

Biederbeck, H. H., Boulay, M. C. and Jackson, D. H. 2001. Effects of hunting regulations on bull elk survival and age structure. - Wildl. Soc. Bull. 29: 1271-1277.

Bender, L. C. and Miller, P. J. 1999. Effects of elk harvest strategy on bull demographics and herd composition. - Wildl. Soc. Bull. 27: 1032-1037.

Boyce, M. S. 1993. Predicting the consequences of wolf recovery to ungulates in Yellowstone National Park. - In: Cook, R. (ed.), Ecological issues on reintroducing wolves into Yellowstone National Park, United States Dep of Interior National Park Service, Washington, D.C., pp. 234-269.

Boyce, M. S. and Gaillard, J.-M. 1992. Wolves in Yellowstone, Jackson Hole, and the North Fork of the Shoshone River: simulating ungulate consequences of wolf recovery. - In: Varley, L. and Brewster, W. (eds), Wolves for Yellowstone? A Report to the US Congress, Volume IV Research \& Analysis. National Park Service, Yellowstone National Park, WY, pp. 4-117.

Boyce, M. S., Sinclair, A. R. E. and White, G. C. 1999. Seasonal compensation of predation and harvesting. - Oikos 87: 419-426.

Burnham, K. P. and Anderson, D. R. 1998. Model selection and inference. - Springer-Verlag.

Caswell, H. 2001. Matrix population models. - Sinauer.

Cook, R. C., Cook, J. G., Murray, D. L. et al. 2001. Development of predictive models of nutritional condition for Rocky Mountain elk. - J. Wildl. Manage. 65: 973-987.

Cook, J. G., Johnson, B. K., Cook, R. C. et al. 2004. Effects of summer-autumn nutrition and parturition date on reproduction and survival of elk. - Wildl. Monogr. 155: 1-61.

Coughenhour, M. B. and Singer, F. J. 1996. Elk population processes in Yellowstone National Park under the policy of natural regulation. - Ecol. Appl. 6: 573-583.

Dumont, A., Crete, M., Ouellet, J. P. et al. 2000. Population dynamics of northern white-tailed deer during mild winters: 
evidence of regulation by food competition. - Can J. Zool. 78: 764-776.

Ebenhard, T. 1988. Introduced birds and mammals and their ecological effects. - Swed. Wildl. Res. 13: 1-107.

Floyd, T. 1995. Top-down impacts on creosotebush herbivores in a spatially and temporally complex environment. - Ecology 77: 1544-1555.

Farnes, P. E. 1996. An index of winter severity. - In: Singer, F. J. (ed.), Effects of grazing by wild ungulates in Yellowstone National Park, US Dept. of Interior, Nat. Park. Serv. Tech. Rep. NPS/NRYELL/96-01. pp. 303-306.

Fuller, T. K. and Sievert, P. R. 2001. Carnivore demography and the consequences of changes in prey availability. - In: Gittleman, J., Funk, S., Macdonald, D. et al. (eds), Carnivore conservation. Cambridge Univ. Press, pp. 163178.

Grange, S., Duncan, P., Gaillard, J. M. et al. 2004. What limits the Serengeti zebra population? - Oecologia 140: 523-532.

Houston, D. B. 1982. The northern Yellowstone elk. - MacMillan.

Huff, D. E. and Varley, J. D. 1999. Natural regulation in Yellowstone Nacional Park's Northern Range. - Ecol. Appl. 9: $17-29$.

Joly, D. O. and Messier, F. 2004. Testing hypotheses of bison population decline in Wood Buffalo National Park: synergism between exotic disease and predation. - Can. J. Zool. 82: $1165-1176$

Jonzén, N., Hedenström, A., Hjort, C. et al. 2002. Climate patterns and the stochastic dynamics of migratory birds. - Oikos 97: 329-336.

Jonzén, N., Pople, A. R., Grigg, G. C. et al. 2005. Of sheep and rain: large-scale population dynamics of the red kangaroo. - J. Anim. Ecol. 74: 22-30.

Lande, R., Engen, S., Saether, B.-E. et al. 2002. Estimating density dependence from population time series using demographic theory and life-history data. - Am. Nat. 159: $321-337$.

Lande, R., Engen, S. and Saether, B.-E. 2003. Stochastic population dynamics in ecology and conservation. - Oxford

Lange, M. 2004. Natural laws in scientific practice. - Oxford.

Lemke, T. O. 2003. Gardiner late elk hunt annual report 2003. - Montana, Fish Wildlife and Parks, Livingston, MT.

Lemke, T. O., Mack, J. A. and Hougston, D. B. 1998. Winter range expansion by the northern Yellowstone elk herd. - Intermountain J Sci. 4: 1-9.

Loison, A., Festa-Bianchet, M., Gaillard, J.-M. et al. 1999. Agespecific survival in five populations of ungulates: evidence of senescence. - Ecology 80: 2539-2554

Mack, J. A. and Singer, F. J. 1993. Using Pop-II models to predict effects of wolf predation and hunter harvests on elk, mule deer, and moose on the Northern Range. - In: Cook, R. S. (ed.), Ecological issues on reintroducing wolves into Yellowstone National Park. US Dept Iinterior, National Park Service, Sci. Monogr. NPS/NRYELL/NRSM-93/22, pp. $49-74$

Mduma, S. A. R., Sinclair, A. R. E. and Hilborn, R. 1999. Food regulates the Serengeti wildebeest: a 40-year record. - J. Anim. Ecol. 68: 1101-1122.

Mech, L. D. and Peterson, R. O. 2002. Wolf-prey relationships. - In: Mech, L. and Boitani, L. (eds), Wolves: behavior, ecology, conservation. Univ. of Chicago Press, pp. 131-160.

Merrill, E. H. and Boyce, M. S. 1991. Summer range and elk population dynamics in Yellowstone National Park. - In: Keiter, R. B. and Boyce, M. S. (eds), The greater Yellowstone ecosystem: redefining America's wilderness heritage. Yale Univ. Press, pp. 263-273.

Messier, F. 1994. Ungulate population models with predation: a case study with north American moose. - Ecology 75: 478 488.

Messier, F., Gasaway, W. C. and Peterson, R. O. 1995. Wolfungulate interactions in the northern range of Yellowstone: hypotheses, research priorities and methodologies. Unpubl. Rep. submitted to U.S Dept of Interior, pp. 24.

Montana Fish Wildlife \& Parks 2004. Harvest and hunting reports. [WWW document]. URL www.fwp.state.mt.us/ hunting/harvest_reports.asp

Murphy, K. M. 1998. The ecology of the cougar (Puma concolor $)$ in the northern Yellowstone ecosystem: interactions with prey, bears, and humans. PhD thesis, Univ. of Idaho, Moscow, Idaho, pp. 147.

National Research Council 1997. Wolves, bears, and their prey in Alaska: biological and social challenges in wildlife management. - National Academy Press, Washington, D.C.

National Research Council 2002. Ecological dynamics on Yellowstone's Northern Range. - National Academy Press, Washington, D.C

Oedekoven, M. A. and Joern, A. 2000. Plant quality and spider predation affects grasshoppers (Acrididae): food-qualitydependent compensatory mortality. - Ecology 81: 66-77.

Pedersen, H. C., Steen, H., Kastdalen, L. et al. 2004. Weak compensation of harvest despite strong density-dependent growth in willow ptarmigan. - Proc. R. Soc. Lond. B 271: $381-385$.

Peterson, R. O. 1977. Wolf ecology and prey relationships on Isle Royale. Natl Park Serv. Sci. Monogr. Ser. No. 11. - U.S. Government Printing Office, Washington, D. C.

Peterson, R. O. 2001. Wolves as top carnivores: new faces in new places. - In: Sharpe, V., Norton, B. and Donnelley, S. (eds), Wolves and human communities. Island Press, pp. $151-160$

Reid, D. G., Krebs, C. J. and Kenney, A. 1995. Limitation of collared lemming population growth at low densities by predation mortality. - Oikos 73: 387-398.

Rosenburg, A. 2000. Philosophy of science. - Routledge, New York.

Royama, T. 1992. Analytical population dynamics. - Chapman \& Hall.

Schmitz, O. J., Hambäck, P. A. and Beckerman, A. P. 2000. Trophic cascades in terrestrial systems: a review of the effects of carnivore removals on plants. - Am. Nat. 155: $141-153$.

Schumacker, R. E. and Lomax, R. G. 1996. A beginner's guide to structural equation modeling. - Lawrence Erlbaum Associates, Mahwah, New Jersey.

Schwartz, C. C. and Haroldson, M. A. 2003. Yellowstone grizzly bear investigations: annual report of the Interagency Grizzly Bear Study Team. U.S. Dept of the Interior, U.S. Geol. Surv. pp. 75

Sinclair, A. R. E. 2003. Mammal population regulation, keystone processes and ecosystem dynamics. - Philos. Trans. R. Soc. Lond. B. 358: 1729-1740.

Sinclair, A. R. E., Mduma, S. and Brashares, J. S. 2003. Patterns of predation in a diverse predator-prey system. - Nature 425: $288-290$.

Singer, F. J., Swift, D. M., Coughenour, M. B. et al. 1998. Thunder on the Yellowstone revisited: an assessment of management of native ungulates by natural regulation, 1968-1993. - Wildl. Soc. Bull. 26: 375-390.

Smith, D. W., Peterson, R. O. and Houston, D. B. 2003. Yellowstone after wolves. - Bioscience 53: 330-340.

Smith, D. W., Drummer, T. D., Murphy, K. M. et al. 2004. Winter prey selection and estimation of wolf kill rates in Yellowstone national park, 1995-2000. - J. Wildl. Manage. 68: $153-166$.

Soulé, M. E., Estes, J. A., Berger, J. et al. 2003. Ecological effectiveness: conservation goals for interactive species. - Conserv. Biol. 17: 1238-1250.

Stapanian, M. A. and Bur, M. T. 2002. Overlap in offshore habitat use by double-crested cormorants and boaters in western Lake Erie. - J. Great Lakes Res. 28: 172-181.

Taper, M. L. and Gogan, P. J. P. 2002. The northern Yellowstone elk: density dependence and climatic conditions. - J. Wildl. Manage. 66: 106-122. 
Tveraa, T., Fauchald, P., Henaug, C. et al. 2003. An examination of a compensatory relationship between food limitation and predation in semi-domestic reindeer. - Oecologia 137: $370-376$.

Vucetich, J. A., Peterson, R. O. and Schaefer, O. L. 2002. The effect of prey and predator densities on wolf predation. - Ecology 83: 3003-3013.

Vucetich, J. A. and Peterson, R. O. 2004. The influence of topdown, bottom-up, and abiotic factors on the moose (Alces alces) population of Isle Royale. - Proc. R. Soc., Lond. B 271: $183-189$.

Wang, G. M., Hobbs, N. T., Singer, F. J. et al. 2002. Impacts of climate changes on elk population dynamics in Rocky Mountain National Park, Colorado, USA. - Climate Change 54: 205-223.
Williams, C. K., Lutz, R. S. and Applegate, R. D. 2004. Winter survival and additive harvest in northern bobwhite coveys in Kansas. - J. Wildl. Manage. 68: 94-100.

Wright, G. 2003. An analysis of the northern Yellowstone elk herd: population reconstruction and selection of elk by wolves and hunters. - Ms Thesis, Michigan Tech. Univ., Houghton, MI, p. 210.

Yodzis, P. 2001. Must predators be culled for the sake of fisheries? - Trends Ecol. Evol. 16: 78-84.

Subject Editor: Esa Ranta 